\title{
Phase-contrast synchrotron microtomography reveals the morphology of a partially visible new Pseudogarypus in Baltic amber (Pseudoscorpiones: Pseudogarypidae)
}

\author{
Hans Henderickx, Paul Tafforeau, and Carmen Soriano
}

\begin{abstract}
Pseudogarypus synchrotron sp.n., a new Eocene fossil pseudoscorpion from Baltic amber is described, propagation phase-contrast X-ray synchrotron microtomography and surface crack restoration with epoxy are used to visualize the morphology, and notes on the other fossil members of the genus are given.

Hans Henderickx. Department of Biology, Universiteit Antwerpen, Groenenborgerlaan 171, 2020

Antwerpen, Belgium (Address for correspondence: Hemelrijkstraat 4, B-2400 Mol,

Paul Tafforeau. European Synchrotron Radiation Facility, 6 rue Jules Horowitz,38043 Grenoble cedex,

Carmen Soriano. European Synchrotron Radiation Facility, 6 rue Jules Horowitz,38043 Grenoble cedex,
\end{abstract} hans.henderickx@pandora.be) France paul.tafforeau@esrf.fr France, carmen.soriano@gmail.com

Key Words: Pseudoscorpion fossil; new species; Baltic amber restoration; propagation phase-contrast Xray synchrotron microtomography

\section{INTRODUCTION}

The Pseudogarypidae Chamberlin, 1923 (Feaelloidea) show a remarkable disjunct distribution with recent species in North America and Tasmania and fossil species in Europe (Benedict and Malcolm, 1978; Harvey, 1996, 1998). Four fossil species have been described from Baltic amber (Harvey, 2011; Henderickx et al., 2006). The fossil inclusions are often only partially preserved or only partially visible (Figure 1.5).

The species have typical specialized chela and some can already be determined with acceptable certainty based on incomplete inclusions (Fig- ure 1.5). However, a new species description is preferably based on a more complete reconstruction, dorsal and ventral, with good drawings of the morphology in the right position. At least one chela should be complete and easily visible from different angles (Henderickx, 2005). Reconstruction illustrations can be based on multi-stacking macro photography, after preparation of the amber surface. Blurring surface cracks can be filled with epoxy and a permanent coating can be applied to prevent the fossil from further deterioration. This coating will also protect the amber matrix from handling and 

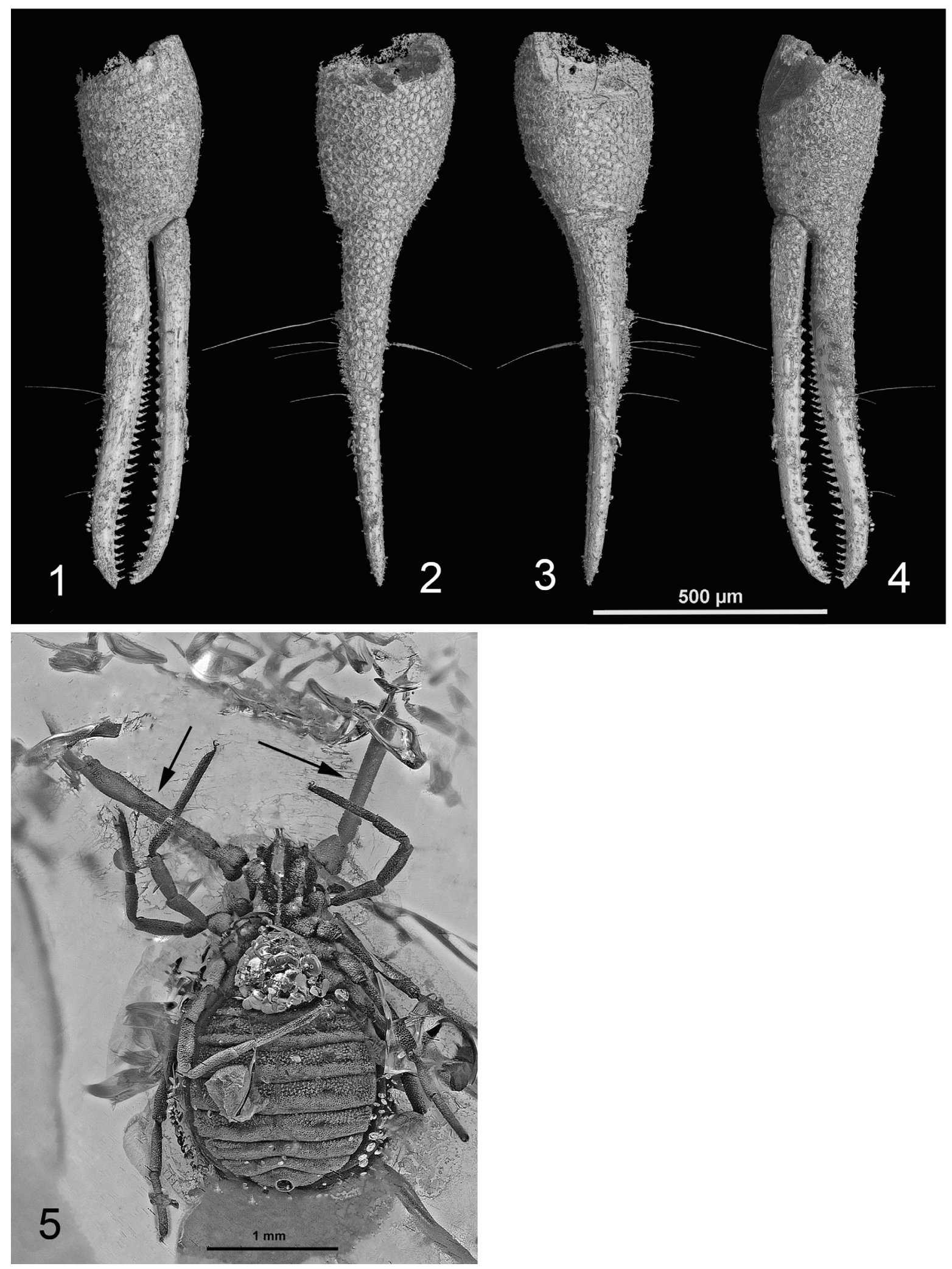

FIGURE 1. Pseudogarypus synchrotron sp.n., holotype, right chelal fingers, PPC-SR $\mu C T$ reconstruction of the pedipalp, at $0.667 \mu$ of voxel size and $50 \mathrm{~mm}$ of propagation distance. 1: paraxial; 2: dorsal; 3:ventral; 4: antiaxal; 5: Pseudogarypus extensus with brood pouch. 
from the fluids in which it is submerged for photography and observation.

Some parts remain invisible for the lens, hidden behind flow lines, internal cracks, opaque amber or the unlucky position of the extremities. This was also the case in the samples examined here, and therefore propagation phase contrast $X$ ray synchrotron microtomography (PPC- $\mu S R C T$ ) was used to reveal the final details (Figure 1.1, 1.2, $1.3,1.4)$. This technique has been extensively used in both opaque and translucent amber research (Tafforeau et al., 2006; Lak et al. 2008; Soriano et al., 2010), allowing the study of external details in the inclusions, hidden to conventional optical techniques, as well as internal anatomy when it is preserved (Perreau and Tafforeau, 2011; Henderickx et al., 2006).

\section{MATERIAL AND METHODS}

Examined here are two pieces of Eocene Baltic amber, obtained from a dealer in Lithuania (holotype) and in the United States (paratype).

Each piece encases a male specimen of a previously unknown Pseudogarypus species, a genus easily recognisable by the irregular carapace with horn-like protuberances, the characteristic cuticular reticulation and the presence of carapaceal alae. The examined and described inclusions, both only partially visible, turned out to be conspecific.

The holotype is an inclusion embedded near the surface in a dark yellow ovoid amber stone, 3.1 gram, $24 \times 16 \times 15 \mathrm{~mm}$ (Figure 2.1).

The dorsal side and one chela are obscured, due to distortions in the amber. The ventral side is turned towards the surface of the amber piece, however, the specimen holds an air bubble, which obscures the larger part of the coxa (Figure 2.2).

The paratype (Figure 3.3 ) is fossilized in a 26 $x 18 \times 10 \mathrm{~mm}$ piece of Baltic amber of 2.4 gram. Tthe underside is covered with opaque whitish amber, 'Baltic mould.' This amber showed another problem: new cracks appeared on the polished surface, probably caused by evaporation of volatiles. Before further manipulation the surface was restored by filling the cracks with low viscosity ARALDITE 2020 epoxy (in ultrasound device, at $40^{\circ} \mathrm{C}$ ), consecutively the sample was embedded in this epoxy (high viscosity) with a rotating device (0.5 mm coating). The treatment allowed a better optical observation and assures permanent protection.

In order to solve some details of the anatomy of the holotype more clearly, the specimen was observed at the European Synchrotron Radiation Facility in Grenoble (France), using a propagation phase contrast protocol at different resolutions. The first scan was performed in ID19 beamline at $2.14 \mu \mathrm{m}$ of voxel size and consisted of 1999 projections, acquired through 360 degrees rotation, with pink beam at $19.1 \mathrm{keV}, 0.3$ seconds of exposure time and $120 \mathrm{~mm}$ of propagation between the sample and the detector (Figure 4).

To resolve in more detail the anatomy of the pedipalps, a second scan with a voxel size of 0.667 $\mu \mathrm{m}$ was performed in beamline BM05, consisting of 1500 projections acquired through 180 degrees rotation, with a $25 \mathrm{keV}$ monochromatic beam, 0.5 seconds of exposure time and $50 \mathrm{~mm}$ between the sample and the detector (Figure 1.1, 1.2, 1.3, 1.4). After the acquisition, the data was reconstructed using a filtered back-projection algorithm adapted for local tomography applications (PyHST @ESRF) and adapted ring artifacts correction protocols (Lyckegaard et al., 2011). Both scans were segmented in three dimensions using manual region growing with VGStudioMax 2.1 (Volume Graphics, Heidelberg, Germany). All microtomographic data, including scan parameters, original and segmented slices, plates, animations and 3D stereolithographic models are available on the online paleontological database of the ESRF (http:// paleo.esrf.eu). Enlarged plastic 3D prints are deposited in the Tervuren Museum with the holotype and at the ESRF.

Optically visible details of both specimens were observed and measured using reflected and translucent illumination on a Leitz microscope and a Canon MP-E objective in combination with Zerene stacker image processing software. All measurements are in $\mathrm{mm}$; (length $=\mathrm{L} \times$ width $=\mathrm{W}$ ), the ratio is the length/width index of an article.

\section{SYSTEMATICS}

Pseudogarypus synchrotron Henderickx sp. $\mathrm{n}$.

\section{Type Material}

Male holotype (Figure 5) in Baltic amber, matrix dimensions $24 \times 16 \times 15 \mathrm{~mm}$. The holotype is deposited in the MRAC, Royal Museum for Central Africa, Tervuren, Belgium (sample nr 236 934). Male paratype in Baltic amber, matrix dimensions $26 \times 18 \times 10$ mm, in coll. Henderickx.

\section{Etymology}

The word "synchrotron" is used here as a noun in opposition. The species epithet refers to 

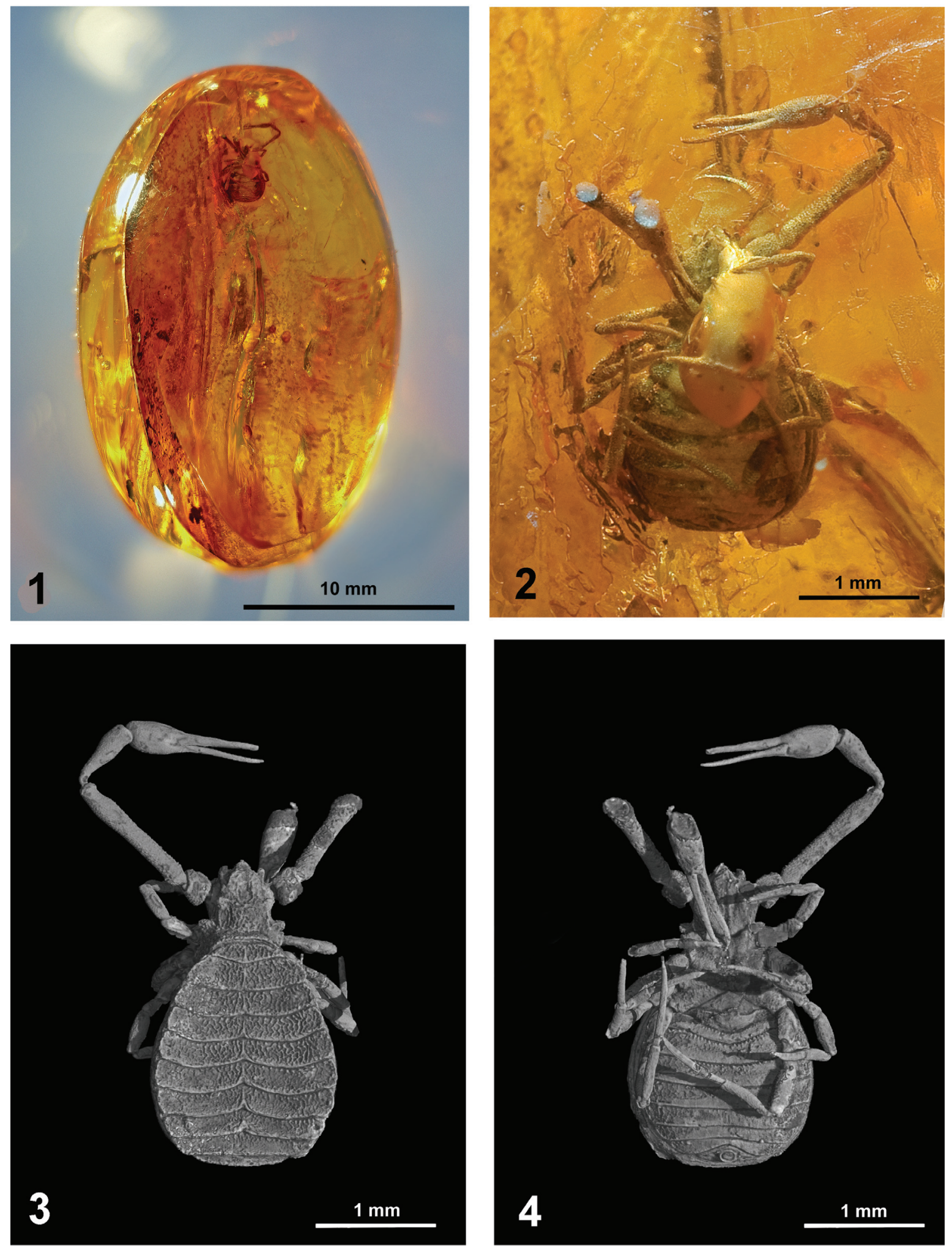

FIGURE 2. Pseudogarypus synchrotron sp.n., holotype. 1: inclusion in matrix (Baltic amber); 2: magnification in visible light; 3: PPC-SR $\mu C T$ 3D reconstruction at PPC-SR $\mu C T$ 3D reconstruction at $5.06 \mu \mathrm{m}$ of voxel size, dorsal view; 4 : ventral view. 

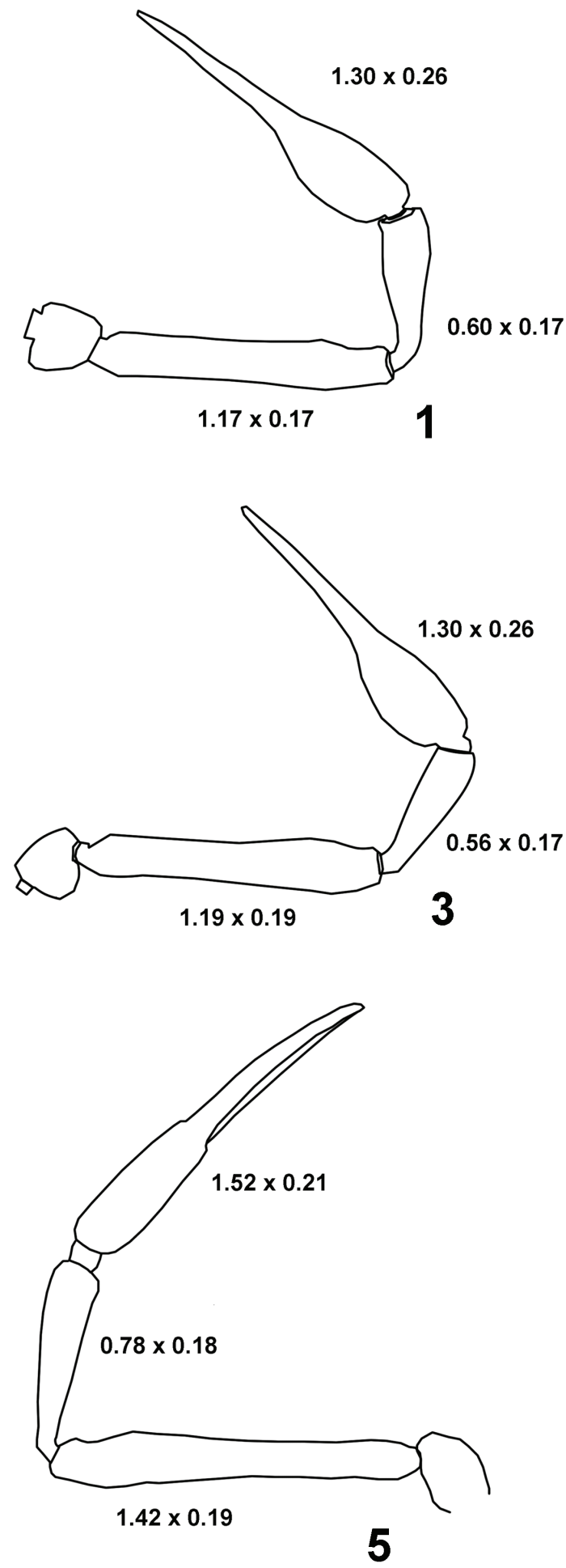
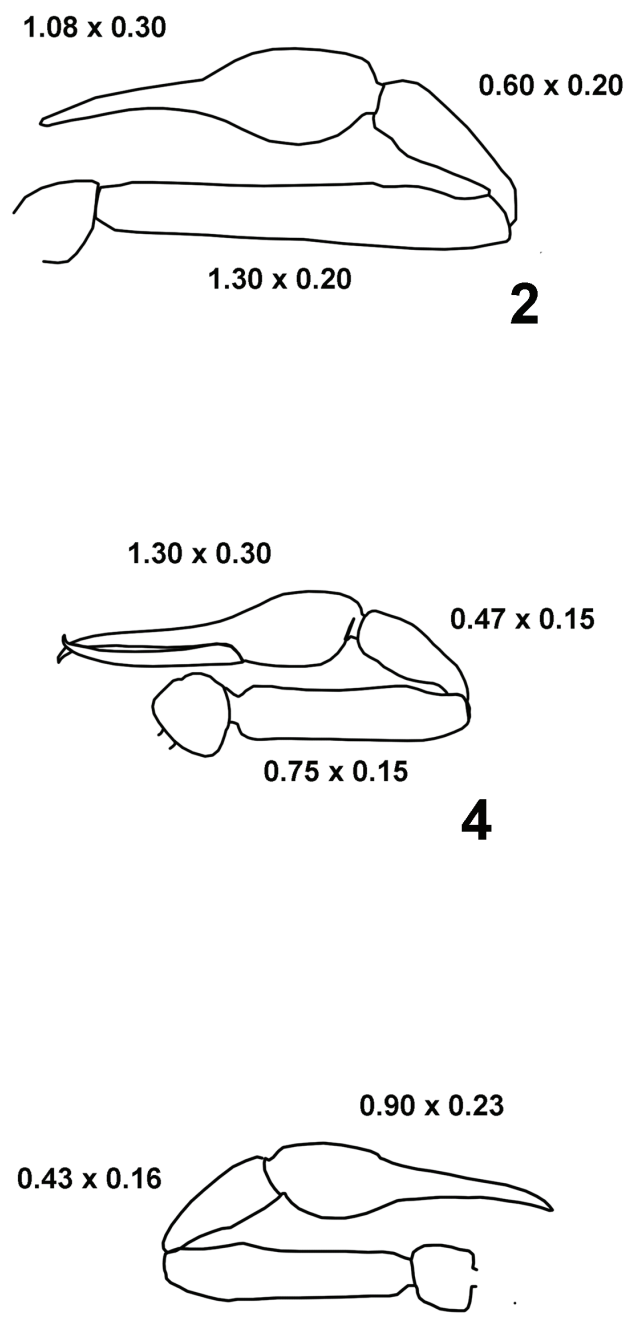

$0.79 \times 0.17$

6

\section{$1 \mathrm{~mm}$}

FIGURE 3. Pseudogarypus synchrotron sp.n., holotype. 1: left chela (mirror view); 2: Pseudogarypus hemprichii, right chela, (according BEIER, 1937); 3: Pseudogarypus synchrotron sp.n., paratype, right chela; 4: Pseudogarypus minor, right chela, (according BEIER, 1947); 5: Pseudogarypus extensus, left chela, (according to BEIER, 1937); 6: Pseudogarypus pangaea, left chela. The dimensions are given in $\mathrm{mm}$. 

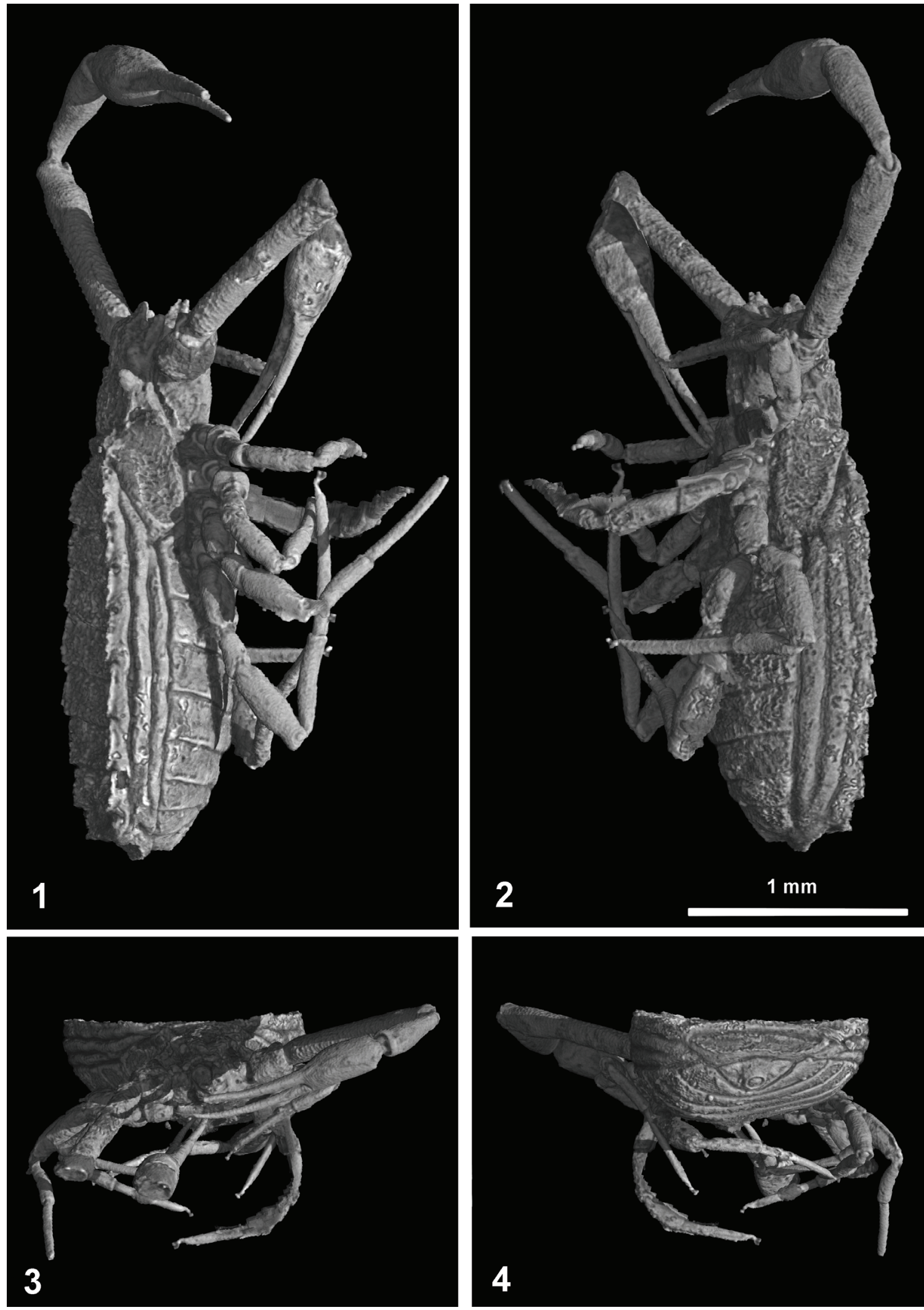

FIGURE 4. Pseudogarypus synchrotron sp.n., holotype, $\mu \mathrm{PPC}-\mathrm{SR} \mu \mathrm{CT}$ reconstruction at $2.14 \mu \mathrm{m}$ of voxel size and $120 \mathrm{~mm}$ propagation distance. 1: right, 2: left, 3: front, 4: rear. 


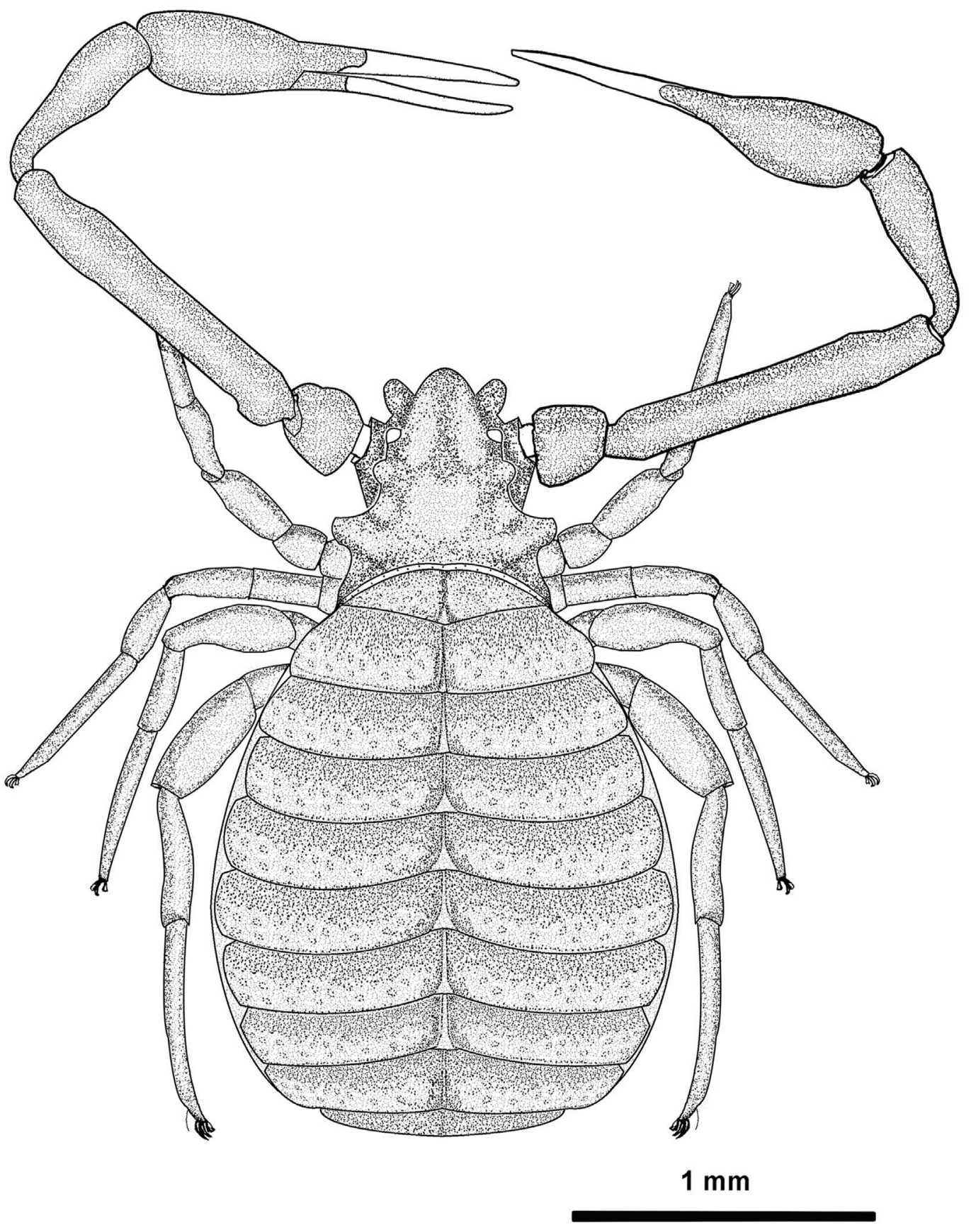

FIGURE 5. Pseudogarypus synchrotron sp.n., holotype, habitus dorsal. 
the equipment that allowed detailed visualization of the optically hidden parts of the fossil.

\section{Diagnosis}

A medium-large sized Pseudogarypus with slender pedipalps. The posterolateral protuberances anterior of the pleural alae are extending very wide. Femur length is more than $1.0 \mathrm{~mm}$ with pedipalpal fingers with moderately spaced regular teeth.

\section{Holotype Description}

Adult male. Habitus Figure 5. Opisthosoma ventrally covered with areas of thin, white emulsion, cuticular structure visible. Colour overall orangeyellowish due to the amber matrix. Ventral side turned towards amber surface, right chela partially missing, distal tip of fixed finger of left chela missing, left leg I and II holding an air bubble which obscures the coxa and genital region, pleural folds visible, tergites and carapace invisible.

Carapace wider than long $(0.87 x$ as long as width, medial measurement), irregular in outline, widened by two large posterolateral protuberances anterior of pleural alae. Anterior margin with relatively deep notch between anterolateral and median protuberances, the latter slightly longer than the anterolateral. Posterior margin elevated into a ridge. First and second pair of eyes about the diameter of one eye spaced, posterior eyes covered with cuticle, anterior eyes facing forward. Cucullar furrow weak, a broad, shallow central depression, which becomes obsolete anteriorly, extending forward from an elevated median disk. Carapace, sclerites, chela and leg cuticle reticulated with an irregular cellular structure. Chaetotaxy of carapace and opisthosoma not visible, chelicerae not observable.

Abdomen longer than wide, ovate $(\mathrm{L} / \mathrm{W}=1.21)$. Pleural membranes raised into three folds (Figure 4.1 and 2), no pleural plates, plaques or sclerite chaetotaxy observable.

The ventral side was only partially observable in visible light, but reconstructed with PPC-SR $\mu C T$ (Figure 2.4). Figure 6.1 shows the coxa and sternites.

No coxal pseudospines could be observed.

Pedipalp (Figure 3.1) with reticulated cuticle, the distal part of the fingers (trichobothrial zone) is smooth. Palpal articles cylindrical in cross-section. Maxilla $2.45 \mathrm{x}$, trochanter $1.00 \mathrm{x}$, femur $6.88 \mathrm{x}$, patella $3.52 \mathrm{x}$, chela (with pedicel) $5 \mathrm{x}$, hand (with pedicel) $2.19 \times$ longer than broad. Femur $1.82 x$ as long as carapace. Movable finger with 4 trichoboth- ria, 4 trichobothria could be observed on the antiaxal side of the fixed chelal finger, position illustrated on Figure 6.5. Fixed finger with 34 , movable fingers with 24 pointed teeth. The teeth in the distal part of the fingers are pointed, moderately spaced, and the most proximal teeth are reduced to small projections (Figure 1.1, 1.4). The teeth on the movable finger are triangular, pointed and on the fixed finger slightly curved proximally. The movable finger is $1.28 \mathrm{x}$ as long as the hand. Each finger has a large terminal or apical tooth (not visible on Figure 1.).

Leg I (Figure 6.2) with trochanter 1.15, femur 1.00 , patella 2.33 , tibia 3.25 , and tarsus $5.42 \times$ longer than broad. Leg IV (Figure 6.3) with trochanter 1.86, femur 1.90 , patella 2,52 , tibia 5.37 and tarsus $10.5 \times$ longer than broad. Arolium shorter than claws.

Measurements (mm). Body length 2.52. Pedipalp: trochanter $0.26 / 0.26$; femur $1.17 / 0.17$; patella $0.60 /$ 0.17 ; chela (with pedicel) 1.30/0.26; hand (with pedicel) $0.57 / 0.26$; movable finger $L=0.73$.

Carapace 0.64/0.74; cucullus L=0.19; anterior ocular diameter 0.06 , posterior eyes covered, diameter with cuticle 0.07 . Leg I: trochanter $0.15 /$ 0.13 ; femur $0.12 / 0.12$; patella $0.28 / 0.12$; tibia 0.26 / 0.08 ; tarsus $0.38 / 0.07$.

Leg IV. trochanter $0.28 / 0.15$; femur $0.19 / 0.10$; patella 0.43/0.17; tibia, 0.43/0.08; tarsus 0.63/0.06.

\section{Remarks}

The shape of the pedipalpal teeth was interpreted from optical microscopy. On the PPC$\mathrm{SR} \mu \mathrm{CT}$ reconstruction there are artefacts at the teeth apex, giving them a longer appearance, especially on the fixed finger. This appearance is probably caused by turbulence in the amber caused by movements of the freshly trapped specimen.

\section{Male Paratype}

Opisthosoma ventrally covered with a thick white emulsion, dorsally partially obscured with white opaque amber. Carapace wider than long $(0.55 \times 0.72,0.76 \mathrm{x})$, irregular in outline as in holotype, the posterolateral protuberances anterior of the pleural alae typically extending wide $(w=0.72$, 0.74 in holotype).

Dimensions. total length 2.53 , dimensions of chela (Figure 3.3, Figure 6.5) femur 1.19/0.19 (6.2 $\mathrm{x})$; patella $0.56 / 0.17(3.29 \mathrm{x})$; chela (with pedicel) $1.30 / 0.26(5 \mathrm{x})$ 

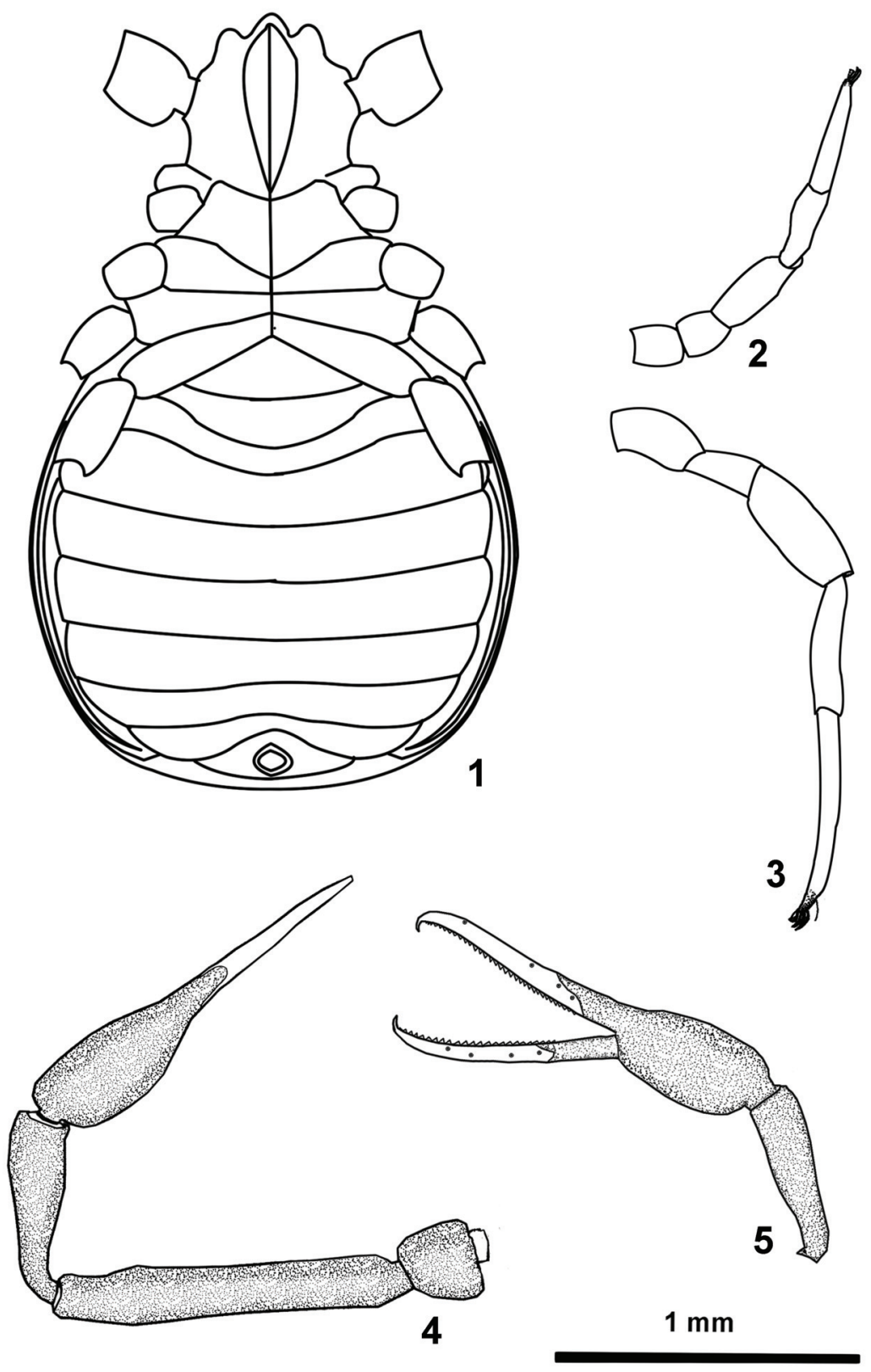

FIGURE 6. Pseudogarypus synchrotron sp.n., holotype. 1: ventral reconstruction with coxae, 2: leg I; 3: leg IV; 4: pedipalp left; 5: $P$. synchrotron sp.n., paratype, left chela with position of trichobothria. 
Fixed finger with 33, movable fingers with 24 teeth .

\section{Discussion}

The new species differs from the other Oligocene fossils Pseudogarypus pangaea Henderickx et al., 2006, Pseudogarypus minor Beier, 1947 and Pseudogarypus hemprichii (Koch and Berendt, $1854)$ by its slender chela $(5 x)$, only the chela of Pseudogarypus extensus Beier, 1937 (L/W=7.23x) is much more slender than all other Eocene Pseudogarypus species including the new species. $P$. synchrotron sp. $\mathrm{n}$. is significant larger than $P$. minor and $P$. pangaea. The finding of two conspecific adult specimens of this new species (Figure $3.1,3.3)$ confirms that the characteristics are not an individual aberrance.

Considering the extant North-American Pseudogarypus species: the posterolateral protuberances anterior of the pleural alae are extending wider than in any other recent species. The troglobitic P. spelaeus Benedict and Malcolm, 1978 has elongated pedipalps with a more slender femur and hand but the chelal teeth of this specimen are widely spaced (Benedict and Malcolm, 1978).

\section{DISTRIBUTION AND ECOLOGY}

Found in Baltic amber, a fossil resin from the Upper Eocene amber forest, dated approximately 46 my. The botanical source of the resin that produced this amber remains unclear. There are mixed signals from suggestions of either an araucarian Agathis-like or a pinaceous Pseudolarix-like resin-producing tree. Although the evidence appears to lean more toward a pinaceous source, a presently extinct common ancestral tree species is probably the only solution (Langenheim, 2003).

\section{ACKNOWLEDGEMENTS}

We are grateful to the ESRF, ID19 and BM05 beamlines that provided the beamtime necessary for these investigations.

Thanks are due to M. Harvey (Perth), V. Mahnert (Genève), J. Bosselaers (Beerse) and the anonymous referees for correcting the manuscript; to M. Veta (Lithuania) for the cooperation in the search for new amber inclusions.

\section{REFERENCES}

Beier, M. 1937. Pseudoscorpione aus dem Baltischen Bernstein. Festschrift zum 60. Geburtstage von Professor Dr. Embrik Strand, 2:302-316.
Beier, M. 1947. Pseudoscorpione im Baltischen Bernstein und die Untersuchung von Bernstein-Einschlüssen. Mikroscopie, 1:188-199.

Benedict, E.M. and Malcolm, D.R. 1978. The family Pseudogarypidae (Pseudoscorpionida) in North America with comments on the genus Neopseudogarypus Morris from Tasmania. Journal of Arachnology, 6:81-104.

Chamberlin, J.C. 1923. The genus Pseudogarypus Ellingsen (Pseudoscorpionida - Feaellidae). Entomological News, 34:146-149, 161-166.

Harvey, M.S. 1996. The biogeography of Gondwanan pseudoscorpions (Arachnida). Revue Suisse de Zoologie, vol. hors série:255-264.

Harvey, M.S. 1998. Pseudoscorpion groups with bipolar distributions: a new genus from Tasmania related to the holarctic Syarinus (Arachnida, Pseudoscorpiones, Syarinidae). The Journal of Arachnology, 26:429-441.

Harvey, M.S. 2011. Pseudoscorpions of the World, version 2.0. Western Australian Museum, Perth. ww.museum.wa.gov.au/catalogues/pseudoscorpions/

Henderickx, H. 2005. A new Geogarypus from Baltic amber (Pseudoscorpiones: Geogarypidae). Phegea, 33 (3):87-92.

Henderickx, H., Cnudde, V., Masschaele, B., Dierick, M., Vlassebroeck, J., and Van Hoorebeke, L. 2006. Description of a new fossil Pseudogarypus (Pseudoscorpiones: Pseudogarypidae) with the use of Xray micro-CT to penetrate opaque amber. Zootaxa, 1305:41-50.

Koch, C.L. and Berendt, G.C. 1854. Die im Bernstein befindlichen Myriapoden, Arachniden und Apteren der Vorwelt. In Berendt, G.C. (ed.) Die im Bernstein Befindlichen Organischen Reste der Vorwelt Gesammelt in Verbindung mit Mehreren Bearbeitet und Herausgegeben 1(2). Nicolai, Berlin.

Lak, M., Neraudeau, D., Nel, A., Cloetens, P., Perrichot, V., and Tafforeau, P. 2008. Phase contrast X-ray synchrotron imaging: Opening access to fossil inclusions in opaque amber. Microscopy and Microanalysis, 14:251-259.

Langenheim, J. 2003. Plant Resins: Chemistry, Evolution, Ecology and Ethnobotany. Timber Press, Portland, Cambridge.

Lyckgaard, A., Johnson, G., and Tafforeau, P. 2011. Correction of ring artifacts in X-ray tomographic images. International Journal of Tomography \& Statistics, 18(F11):1-9.

Perreau, M. and Tafforeau, P. 2011. Three new species of Leiodidae (Coleptera) from Baltic amber: pushing further the paleoentomological descriptions by virtual dissection of fossils using phase-contrast X-ray synchrotron microtomography. Systematic Entomology, 36:573-580. 
Soriano, C., Archer, M., Azar, D., Creaser, P., Delclos, X., Godthelp, H., Hand, S., Jones, A., Neraudeau, D., Ortega-Blanco, J., Perez-De La Fuente, R., Perrichot, V., Saupe, E., Solorzano-Kraemer, M., and Tafforeau, P. 2010. Synchrotron X-ray imaging of inclusions in amber. Comptes Rendus Palevol, 9:361-368.
Tafforeau, P., Boistel, R., Boller, E., Bravin, A., Brunet, M., Chaimanee, Y., Cloetens, P., Feist, M., Hoszowska, J., Jaeger, J.J., Kay, R.F., Lazzari, V., Mariva, L., Nel, A., Nemoz, C., Thibault, X., Vignaud, P., and Zabler, S. 2006. Applications of X-ray synchrotron microtomography for non-destructive 3D studies of paleontological specimens. Applied Physics A: Materials, Science and Processing, 83:195202. 